\title{
Los regocijos de un Estado liberal: la discusión en las Cortes Generales y Extraordinarias de Cádiz sobre las fiestas que celebrarían a la monarquía constitucional
}

\author{
María José Garrido Asperó*
}

\section{Resumen}

Este artículo recoge las propuestas hechas por algunos diputados en las Cortes de Cádiz para festejar anualmente la soberanía nacional, el poder legislativo y la igualdad política de los españoles. Plantea que esas propuestas y las disposiciones emitidas por las Cortes fueron la expresión festiva de la revolución política liberal.
Abstract

This paper analyses the proposals made by the deputies at the Courts of Cadiz to celebrate annually the national sovereignty, the Legislative power and political equality of all Spaniards. It sets forth the idea that those proposals and the dispositions decreed by the Courts were the festival expression of the liberal political revolution.
Palabras clave:

independencia, liberalismo, Cádiz, soberanía, fiestas.
Fecha de recepción: mayo de 2000

Fecha de aceptación: septiembre de 2000

*Investigadora del Instituto de Investigaciones Dr. José María Luis Mora adscrita al área de Historia Social y Cultural. Correo electrónico: mgarrido@institutomora.edu.mx 


\section{UN NUEVO ESTADO}

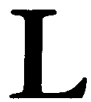

a crisis política del imperio español, desatada tras la invasión napoleónica a la península y la ausencia del poder legítimo de la monarquía, desencadenaron una serie de acontecimientos que culminaron con el establecimiento de una distinta organización política apoyada en un también distinto principio legitimador del poder: la soberanía nacional.

La formación de juntas en España, la resistencia popular contra la invasión francesa y el accidentado proceso de creación de un gobierno nacional que actuara a nombre del rey fueron, como señala François Xavier Guerra, la expresión de una legitimidad contraria a la de Napoleón, a la de las autoridades peninsulares que lo habían reconocido y a las abdicaciones de los monarcas españoles. ${ }^{1}$

El proceso, sin proponérselo, no terminaría ahí. El vacío de poder, la crisis de las instituciones tradicionales de la monarquía, la debilidad militar, la poca claridad política de las dos instituciones que suplieron al monarca durante los primeros años de cautiverio -la Junta Central y el primer Consejo de Regencia-, el peculiar proceso de convocatoria y reunión de las Cortes y la habilidad o buena fortuna del grupo que con el tiempo se identificaría como liberal, permitieron que la discusión sobre las cualidades que debía tener el gobierno provisional tomara un rumbo distinto.

De proponerse un gobierno que con base en las instituciones tradicionales

${ }^{1}$ Guerra, Modernidad, 1992, p. 43. del Antiguo Régimen y en la constitución histórica de la monarquía española debía solamente proveer de una autoridad legítima que absorbiera temporalmente los atributos soberanos, gobernara a la monarquía con las leyes tradicionales y organizara la defensa del imperio, se introdujeron en la discusión los peligrosos temas de la naturaleza del Estado, el de la soberanía nacional y el de sus formas de representación.

Las Cortes Generales y Extraordinarias sesionaron del 24 de septiembre de 1810 al 20 de septiembre de 1813 , después de un largo y accidentado proceso de convocatoria. ${ }^{2}$ Los diputados presentes el día de la apertura establecieron un sistema político nuevo fundamentado en los principios liberales. Juraron a Fernando VII como legítimo rey de la monarquía española; declararon nulas las abdicaciones de Bayona no sólo por la violencia que intervino en aquellos actos, también por carecer del consentimiento de la nación; decretaron que en las Cortes residía la soberanía de la nación representada por sus diputados, ésta la poseían por sí y no por delegación o a nombre de Fernando VII; se instituyeron en constituyentes atribuyéndose una capacidad

${ }^{2}$ Sobre el proceso de convocatoria y reunión de las Cortes, la gestión de la Junta Central y los Consejos de Regencia, la formación de los grupos políticos y sus proyectos de gobierno véase: Marcuello, "Cortes", 1991, pp. 67 a 103; Flaquer, "Ejecutivo", 1991, pp. 37 a 66; Morán, "Formación", 1991, pp. 13 a 36; Artola, "Monarquía", 1991, pp. 105 a 124; Suárez, Cortes, 1982; Hamnetr, Politita, 1985; Anna, España, 1983; Rodríguez, Independencia, 1998, y Chust, Cuestión, 1999. 
legislativa ilimitada; enunciaron la división de poderes otorgando a la Regencia el ejecutivo, a la que se impuso la obligación de jurar y obedecer a las Cortes y las disposiciones que de ella emanaran. ${ }^{3}$

Así, las Cortes, que en principio se reunirían para salvar al Estado absoluto de la grave crisis a la que Napoleón lo sometió, concluyeron siendo y representando la lucha contra el despotismo de la monarquía española. La crisis desatada por la invasión condujo al rompimiento con la teoría absolutista de la legitimidad real del poder.

Sin monarca, la soberanía antes depositada en la corona fue transferida a la nación. A ésta correspondía la facultad de pactar su existencia política estableciendo sus leyes fundamentales; el origen legítimo del poder, antes divino, fue depositado en la voluntad de la nación integrada por los españoles de ambos hemisferios y ejercida, en su nombre, por los ciudadanos diputados representantes. ${ }^{4}$

En este artículo proponemos que las discusiones legislativas sobre las que debían ser las fiestas de la monarquía constitucional fueron expresión de los grandes temas puestos a debate por la revolución política liberal, y que esos festejos permitirían inculcar una identidad nacional basada en los mitos fundacionales de ese sistema político: la soberanía nacional, la preponderancia

3 Decreto I de las Cortes, 24 de septiembre de 1810 en Colección, 1820-23, vol. I, pp. 1 a 3.

4 "Constitución", tít. I, cap. I, artículos 1 y 3; tít. III, cap. 1, artículos 27,28 y 29, en Hernández y Dávalos, Colección, 1877-1882, vol. IV, pp. 87 y 89 . del poder legislativo y la igualdad de representación política.

Esas discusiones también nos permiten plantear que las modificaciones hechas al calendario festivo de la monarquía estuvieron condicionadas, al menos en parte, por el desacuerdo entre los diputados de la península y los americanos en torno al problema de la igualdad de representación.

Los aniversarios de la promulgación de la Constitución de Cádiz en todo el territorio de la monarquía; el de la instalación de las Cortes Generales y Extraordinarias en territorio peninsular, y la abolición del paseo del real pendón de las ceremonias con que los antiguos súbditos de los territorios ultramarinos conmemoraban anualmente su conquista o fundación, fueron los festejos discutidos y aprobados por los diputados de las Cortes liberales.

El primero simbolizaría el rompimiento con el Antiguo Régimen y la adopción de la soberanía nacional como el nuevo argumento legitimador del poder político. El segundo revela que el poder legislativo fue pensado, como ha señalado Miguel Artola, como el poder preponderante en el ejercicio político al que debían quedar subordinados el ejecutivo y el judicial, dada su relación con la expresión de la voluntad nacional, ${ }^{5}$ y el tercero, pretendía ejemplificar la igualdad política de los españoles de ambos hemisferios. Igualdad prometida en el sistema de representación parlamentaria, pero negada en la práctica a los ultramarinos.

Pese a que las fuentes con que contamos para el análisis de las fiestas son

"Artola, "Monarquía", 1991, pp. 105 a 106. 
vastas y diversas, he recurrido principalmente al Diario de las discusiones y actas de las Cortes y a la Colección de los decretos $y$ órdenes expedidos por las mismas. Estas fuentes sirven para analizar las discusiones políticas legislativas sobre el calendario festivo de la monarquía constitucional en relación con los grandes temas planteados por la revolución liberal y no para efectuar el análisis de lo sucedido en torno a las fiestas en un espacio geográfico específico de la monarquía. Análisis que excede los objetivos planteados para este artículo. ${ }^{6}$

\section{EL PODER LEGISLATIVO}

A partir del 25 de septiembre de 1810 las Cortes se ocuparon de señalar con festejos públicos los asuntos destacados en la vida política y militar del imperio. Ese día dispusieron que el Consejo de Regencia comunicara a todos los habitantes de la monarquía la gloriosa instalación del Congreso $\mathrm{Na}$ cional, haciendo festejos dignos de tal acontecimiento. Todo con la pompa y solemnidad que las circunstancias militares de cada región permitieran. ${ }^{7}$ Pronto, con la conciencia de que iniciaban una época nueva, se ocuparon de

\footnotetext{
${ }^{6}$ Sobre la manera en que se celebraron los aniversarios señalados y los desacuerdos políticos que generaron entre las autoridades residentes en la ciudad de México, véase: Garrido, "Fiesta", 1996, y "Fiestas", 2000.

7 Ordenaron se hicieran las ceremonias comunes: "que se cante en todos los dominios de S. M. un solemne te deum en acción de gracias, se hagan salvas de artillería en celebridad de tan memorable acontecimiento, $y$ rogativas públicas por
}

festejar el tema esencial de la revolución liberal: la soberanía nacional y el poder legislativo donde se ejercía esa soberanía.

La ceremonia anual en honor a la instalación de las primeras Cortes modernas de Hispanoamérica fue un claro acto de poder político. Todos los años debía el ejecutivo, es decir, el Consejo de Regencia, renovar el juramento de obediencia dispuesto por las Cortes aquel histórico 24 de septiembre de 1810.

El 22 de septiembre de 1811, el diputado Manuel García Herreros, de la provincia de Soria, propuso que se solemnizara el primer aniversario de la instalación de las Cortes. ${ }^{8}$ Ceremonia en la que las autoridades principales reunidas en Cádiz -el Consejo de Regencia, los jefes militares, los tribunales y demás corporaciones- debían renovar el juramento de lealtad y obediencia hecho a las Cortes del mismo modo que lo hicieron en virtud del decreto del 24 de septiembre de 1810 . Bajo la fórmula de:

\begin{abstract}
¿Reconocéis la soberanía de la nación representada por los diputados de estas Cortes Generales y Extraordinarias?, ¿juráis obedecer sus decretos, leyes y constitución que se establezca según los santos fines para que se han reunido, y mandar observarlos y hacerlos ejecutar?"
\end{abstract}

tres días, implorando el auxilio divino para el acierto". Decreto III de las Cortes, 25 de septiembre de 1810 en Colección, 1820-23, vol. I, p. 6.

${ }^{8}$ Sesión de las Cortes del 22 de septiembre de 1811 en Diario, 1811-1823, vol. viII, p. 403.

9 Decreto I de las Cortes, 24 de febrero de 1810 en Colección, 1820-23, vol. I, p. 2. 


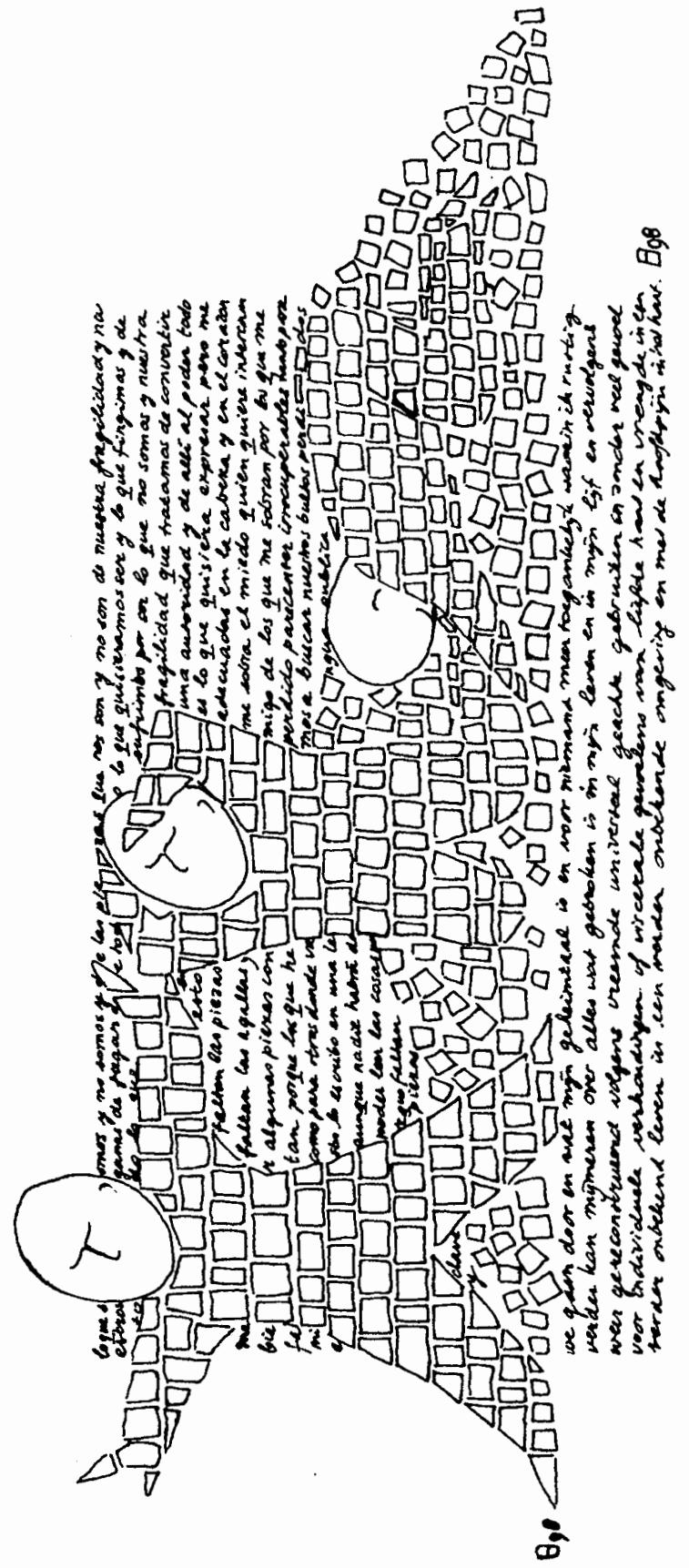


Otras voces solicitaron que estos festejos fueran acompañados de una misa con Te deum en la iglesia catedral de Cádiz, para dar gracias a Dios por la manera en que se congregaron las Cortes y por la importante labor que estaban realizando. El diputado por $\mathrm{Va}$ lencia, Joaquín Lorenzo Villanueva, propuso en esa misma sesión que esta ceremonia se extendiera a todo el territorio nacional y se perpetuara celebrándose anualmente el mismo día 24 de septiembre. Pese a que su petición fue aprobada, el decreto emitido por las Cortes ordenó se hiciera esta ceremonia solamente en Cádiz. ${ }^{10}$

Al año siguiente retomaron el tema. En la sesión del 23 de septiembre de 1812 los diputados aprobaron la proposición hecha el día anterior en sesión secreta por el señor Martínez Tejada sobre que todos los 24 de septiembre se conmemorara el día de la instalación de las Cortes. En la orden expedida ese mismo día, una vez más omitieron fuera extensivo a todo el territorio de la monarquía. ${ }^{11}$ Probablemente decidieron limitar la fiesta del poder legislativo al espacio peninsular porque desde el día de la instalación de las Cortes los diputados americanos exigieron a los peninsulares la igualdad de representación parlamentaria. Petición que, como se sabe, generó importantes conflictos. En este contexto pudo ser que los diputados peninsulares con-

${ }^{10}$ Decreto XCIV de las Cortes, 22 de septiembre de 1811 en Colección, 1820-23, vol. I, p. 235.

11 Orden de las Cortes, 23 de septiembre de 1812 en Colección, 1820-23, vol. III, p. 92, y sesión de las Cortes del 23 de septiembre de 1812 en Diario, 1811-1823, vol. Xv, p. 273. sideraran poco conveniente trasladar la ceremonia del poder legislativo a los territorios ultramarinos.

\section{La SObERANía NACIONAL}

El gran festejo nacional de la monarquía liberal fue la promulgación de la Constitución de Cádiz y la conmemoración de sus aniversarios en todos los territorios de la monarquía. La serie de significados que los diputados de las Cortes Generales y Extraordinarias depositaron en esa ceremonia se hace evidente con la elección del día en que se juró y promulgó solemnemente por las autoridades de la monarquía liberal y los habitantes de la ciudad de Cádiz.

Los diputados eligieron el 19 de marzo por recordar ese día el acontecimiento que entonces interpretaron como el inicio de la gran revolución y del rompimiento con el despotismo.

tenga efecto [la promulgación] en uno de los [días] más señalados de su santa insurrección, como el 19 de marzo, aniversario del que por la espontánea renuncia de Carlos IV subió al trono de las Españas su hijo [...] y cayó para siempre el régimen arbitrario del anterior gobierno, abriendo un largo campo a las esperanzas de la nación, y a los heroicos hechos de su lealtad y patriotismo. ${ }^{12}$

Esta fiesta debía honrar al rey "Deseado", Representaba el principio de la lucha contra el poder despótico y las

12 Decreto cxxxvil de las Cortes, 14 de marzo de 1812 en Colección, 1820-23, vol. II, p. 94. Las cursivas son mías. 
instituciones tradicionales de la monarquía. Ramón Solís sostiene que los diputados eligieron ese día porque además coincidía con el de los Josés, y así creían que arruinaban los festejos que la España ocupada rendiría al rey José I, José Bonaparte. ${ }^{13}$

Esta nueva fiesta coincidió, como otras, con una ceremonia tradicional del calendario religioso, lo que sin duda debe haber contribuido a que luciera más la promulgación de la Constitución y la celebración de sus aniversarios, haciendo uso de los adornos y disposiciones comunes al día del santo. Sin embargo, me parece muy importante subrayar aquí que ni en el Diario de las discusiones y actas de las Cortes, ni en los decretos emitidos por el legislativo relativos a esta ceremonia se hicieron consideraciones de tipo religioso en la elección del día destinado a la conmemoración anual de la promulgación de la Constitución.

Los legisladores discutieron por primera vez la posibilidad de hacer del 19 de marzo el día de festejo nacional de la monarquía liberal, en la sesión del 15 de marzo de 1813 , cuando el secretario de Gobernación de la península y el Consejo de Regencia lo propusieron a las Cortes. Ellos sugerían que se celebrara con besamanos, misa, Te deum, iluminación, salvas de artillería con todos los ejércitos y en todas las plazas de la monarquía, y sugerían que la corte se vistiera de gala, lo que así ordenaron. ${ }^{14}$

13 Solis, Cádiz, 1958, p. 287.

${ }_{14}$ Hasta antes de esta fecha, las Cortes sólo habían resuelto que se anotara en los calendarios señalando el día como aniversario de la promul-
Hay dos aspectos de esta fiesta que me interesa resaltar. El primero se refiere al sentido que los diputados le dieron como fundamento del nuevo orden sociopolítico y a lo que esperaban producir en la comunidad celebrante con ese festejo. En el decreto por el cual ordenaron su celebración argumentaron que así debía hacerse porque ese día:

es el recuerdo más digno del aprecio y consideración de los buenos y leales españoles, por haber recibido en aquel día el código sagrado de su libertad $y$ de sus derechos [...] para fijar más y más la memoria de tan fausto día, avivando el espiritu público, y exaltando el entusiasmo nacional. 15

El otro aspecto se refiere a un interesante problema que surgió cuando el diputado Joaquín Lorenzo Villanueva propuso que el Congreso acudiera en cuerpo a la función anual de la promulgación de la Constitución. Otros diputados, cuyos nombres no fueron registrados en el Diario de las discusiones y actas de las Cortes, observaron que esta asistencia podría ocasionar inconvenientes y etiquetas estando en España el rey, que para esa fecha permanecía aún en cautiverio, "a quien como monarca pertenecían todas las distinciones exteriores de la soberanía". ${ }^{16} \mathrm{Ra}-$

gación de la Constitución. Orden de las Cortes, 5 de mayo de 1812 y decreto ccxxxiv, 15 de marzo de 1813 en Colección, 1820-23, vol. 11, p. 206 y vol. IV, pp. 11.

15 Decreto ccxxxiv de las Cortes, 15 de marzo de 1813 en Colección, 1820-23, vol. IV, p. 11. Las cursivas son mías.

16 Sesión de las Cortes del 15 de marzo de 1813 en Diario, 1811-1823, vol. XVII, p. 433. Las cursivas son mías. 
zón por la cual fue desechada la propuesta. Es interesante observar que si bien los diputados de las Cortes estaban convencidos de que era el poder legislativo el preponderante en el proceso político y que ellos eran los representantes de la soberanía nacional, dejaran las "manifestaciones exteriores" de la soberanía al monarca, al ejecutivo.

\section{¿IGUALDAD PARLAMENTARIA?}

El 7 de enero de 1812 las Cortes Generales y Extraordinarias decretaron la abolición del paseo del real pendón en todas las ciudades de América. ${ }^{17}$ Ordenaron se hicieran sólo las funciones de iglesia en las ciudades en que se acostumbraba hacer el paseo el día en que conmemoraba su conquista o fundación. ${ }^{18}$

La abolición del paseo del pendón debe necesariamente analizarse como parte de la discusión que los diputados americanos sostuvieron con los peninsulares para resolver la igualdad de representación ultramarina ante las autoridades que suplieron desde $1808 \mathrm{al}$ monarca: la Junta Central, el primer

\footnotetext{
17 Ésta era la fiesta cívica más importante de la monarquía absoluta. Simbolizaba la renovación anual de la lealtad de los súbditos americanos al monarca español. Desde 1528 la ciudad de México celebraba el aniversario de la conquista haciendo el paseo del real pendón, misa y sermón en la iglesia de San Hipólito los días 12 y 13 de agosto. Garrido, "Fiesta”, 1996.

18 Decreto de abolición del paseo del real pendón dado por las Cortes Generales y Extraordinarias y el Consejo de Regencia el 7 de enero de 1812. Archivo Histórico del Distrito Federal (en adelante AHDF), Historia pendón, inv. 2277, año 1812, exp. 27.
}

Consejo de Regencia y principalmente en el seno del poder legislativo, las Cortes Generales y Extraordinarias.

El gobierno peninsular sabía bien que para organizar una defensa que tuviera posibilidades reales de combatir a Napoleón debía contar con la lealtad y el apoyo económico de las posesiones ultramarinas; que para mantener la frágil unidad del imperio, evitar que surgieran más brotes independentistas y dar legitimidad a sus disposiciones debía incluir a los americanos en el proyecto de nación que se estaba gestionando. Por ello y por la actividad política de los liberales Manuel José Quintana y Lorenzo Calvo de Rozas, la Junta Central expidió el 22 de enero de 1809 la real orden que, entre otras cosas, convocaba a los americanos a enviar a sus representantes a esa corporación de gobierno. ${ }^{19}$

Este importante decreto significó el reconocimiento de los territorios de ultramar como partes integrantes de la monarquía. Desde ese momento, la Junta planteó el problema central de la revolución política de la América española: la definición del concepto de soberanía y, con él, el de su representación. La igualdad se convirtió entonces en la demanda fundamental, la desigualdad en el principal agravio. Inició el proceso que culminó con la declaración formal de la igualdad americana, aunque en la práctica ésta no se le otorgó.

La calidad inferior atribuida a América quedó del todo descubierta con la

19 Decreto de la Junta Central sobre próxima convocatoria a Cortes, Sevilla, 22 de mayo de 1809 en Díaz-Pla, Historia, 1983, p. 73. 
desigual representación de diputados, primero a la Junta Central y luego en las mismas Cortes. Para la Junta ultramar contaría con un diputado por cada virreinato y capitanía general, mientras que la península estaría representada por dos diputados de cada provincia. ${ }^{20}$

Para las Cortes Generales y Extraordinarias de Cádiz, el hemisferio americano estaría representado por un diputado por cada capital de provincia de los virreinatos de Nueva España, Perú, Santa $\mathrm{Fe}$, Buenos Aires, y de las capitanías generales de Puerto Rico, Cuba, Santo Domingo, Guatemala, Provincias Internas, Venezuela y Chile. La real orden disponía que los diputados en las sesiones de éstas, las primeras Cortes, se encargarían de establecer la forma y proporción constante de su representación para las que se celebraran en lo sucesivo, corrigiendo entonces lo que las urgencias del tiempo no permitieron hacer para éstas. ${ }^{21} \mathrm{La}$ península contaría con un representante por cada ciudad peninsular que hubiera participado en las últimas Cortes, las de 1789, más un representante por cada junta provincial peninsular y uno por cada 50000 habitantes peninsulares. ${ }^{22}$

${ }^{20}$ Real orden de la Suprema Junta Central Gubernativa de España y las Indias, Real Palacio del Alcázar de Sevilla, 22 de enero de 1809, en AHDF, Elección de diputados a Cortes, inv. 870, año 1809, exp. 1; Anna, España, 1983, pp. 82 y 83.

${ }^{21}$ Real orden del Consejo de Regencia, Isla de León, 14 de febrero de 1810 en AHDF, Elección de diputados a Cortes, inv. 870, año 1810 , exp. 5 .

22 Anna, España, 1983, p. 91; Caída, 1987, p. 120; Hamnett, Politica, 1985, p. 73; Chust, Cuestion, 1999, p. 37.
Pese a declarar constantemente que a estos territorios correspondían los mismos derechos y prerrogativas que a los de la península y basarse las convocatorias para la Junta y luego para las Cortes en los eternos principios de "equidad y justicia", la representación americana fue intencionalmente disminuida. Por muy liberales que fueran, los peninsulares no estaban dispuestos a ceder el control de las Cortes, que por la superioridad numérica del continente americano y por el criterio de representación proporcional a la población, habrían perdido. ${ }^{23}$

Tan pronto como fue planteado por los americanos el problema de la igualdad, inició la prolongada disputa de intereses. Fueron necesarias varias acaloradas sesiones para que América lograra victorias parciales y confirmara la poca voluntad peninsular para otorgar en la práctica la igualdad de representación parlamentaria. Sólo meses más tarde, por los cuestionamientos que los diputados de ultramar hicieron denunciando la ilegitimidad de unas Cortes compuestas tan inequitativamente, por las noticias de los levantamientos independentistas y ante la amenaza de los americanos de retirarse del legislativo, lograron éstos la igualdad de representación, aunque no para las que se estaban celebrando, sino para las futuras Cortes. ${ }^{24}$

${ }^{23}$ Se calculaba que América tenía una población de entre 15 y 16000000 , España sólo diez.

${ }^{24} \mathrm{La}$ Constitución Política de la Monarquía Española, promulgada en 1812, fijó la igualdad de representación para la futuras Cortes. En el tít. III, cap. I, artículos 28 y 31 quedó establecido que la base de la representación era la misma para 
En la primera sesión del legislativo los diputados americanos suplentes solicitaron, sin éxito, la representación equitativa. El 25 de septiembre de 1810 propusieron que la publicación en ultramar del decreto de instalación fuera acompañado de "varias aclaraciones en favor de aquellos súbditos". Las Cortes dispusieron que una comisión propusiera a la mayor brevedad cómo convendría publicar en América el decreto de instalación.

La comisión integrada sólo por diputados americanos recomendó esa misma tarde que, con base en la "necesidad, justicia y conveniencia", el decreto fuera acompañado de declaraciones que abundaran en la igualdad de derechos que poseían y reconocían las Cortes entre americanos y peninsulares, y enunciara la extensión de su representación en las Cortes nacionales.

Los peninsulares votaron por posponer la discusión. Argumentaron que tales medidas eran intempestivas $\mathrm{y}$ que para proceder con rectitud era necesario tener los antecedentes del caso. Antecedentes inexistentes, pues era ésta la primera ocasión en que América participaba en el gobierno de la monarquía. ${ }^{25}$

En este ambiente se expidió el decreto que constituyó la declaración

ambos hemisferios, que por cada 70 mil almas habría un diputado. Fueron excluidos los negros, las castas, los sirvientes y todos los que según el tít. II, cap. IV, artículos 24 a 26 no satisficieran la calidad de ciudadano. "Constitución" en Hernández y Dávalos, Colección, 1877-1882, vol. IV, pp. 88 y 89.

25 Sesión de las Cortes del 25 de septiembre de 1810 en Diario, 1811-1823, vol. 1, p. 10; Suárez, Cortes, 1982, p. 75. formal de la igualdad de los españoles en ambos hemisferios. Todos los americanos blancos, indios y mestizos fueron desde el 15 de octubre de 1810 iguales a los habitantes de la península. Sin embargo, este decreto tampoco estableció la igualdad política pues, además de excluir a las castas y a los negros, señalaba que quedaría a cargo de las Cortes Extraordinarias:

tratar con oportunidad y con particular interés de todo cuanto pudiera contribuir a la felicidad de los de ultramar, como también sobre el número y forma que debía tener para lo sucesivo la representación nacional en ambos hemisferios. ${ }^{26}$

Esa solución obviamente no satisfizo a los americanos. El 16 de diciembre de 1810 presentaron a las Cortes una Representación en la que enumeraban los principales agravios padecidos por América y señalaban los que a su juicio eran los motivos de las insurrecciones independentistas que, para entonces, recorrían el continente americano, y proponían las medidas para resolverlas. La primera petición solicitaba formalmente que la representación nacional ultramarina fuera la misma en orden y forma a la peninsular. ${ }^{27}$ Las Cortes destinaron varias sesiones a la discusión de las peticiones americanas y dejaron para el final la discusión de la principal demanda, la representación igualitaria.

26 Decreto $v$ de las Cortes, 15 octubre de 1810 en Colección, 1877-1882, vol. I, p. 10.

27 Sesión de las Cortes del 20 de enero de 1811 en Diario, vol. III, p. 41; Alamán, Historia, 1990 , vol. III, pp. 14 y 15. 


\section{SECUENCIA}

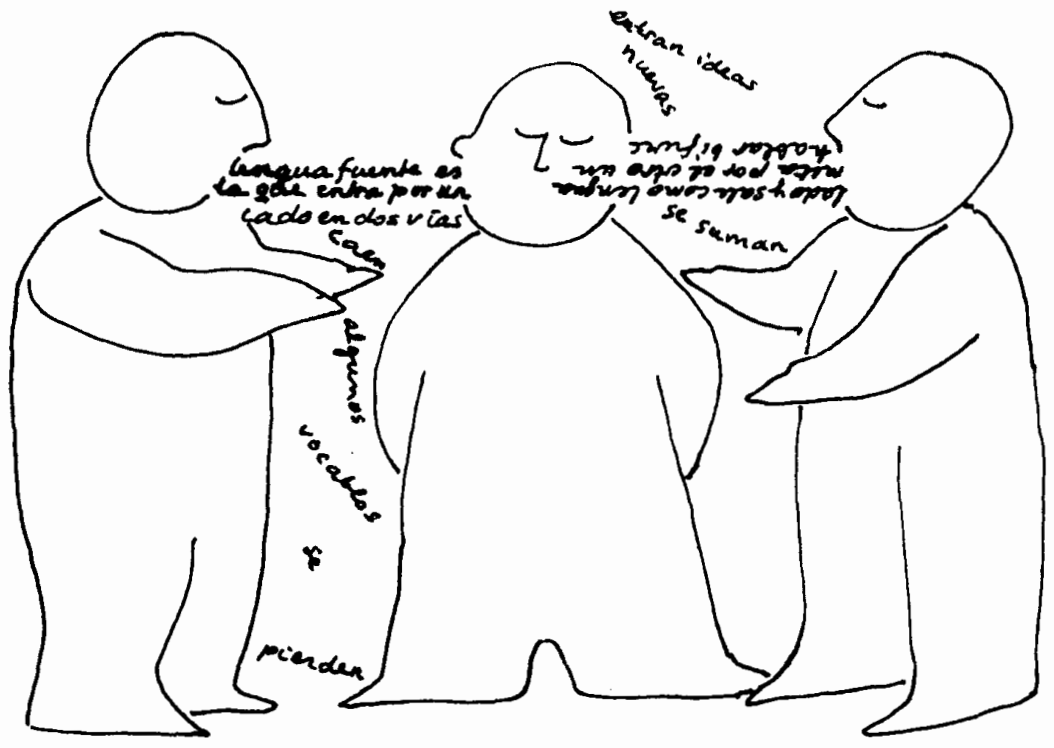


Los peninsulares argumentaron siempre que las Cortes eran extraordinarias, que se habían reunido para salvar al Estado de las graves circunstancias por las que atravesaba, que por la presencia del ejército invasor y porque América nunca había participado en el gobierno había sido imposible determinar con toda justicia la representación de aquellos territorios, pues carecían de la información necesaria; señalaron, además, que el sistema de representación era aún imperfecto, que estaban por decidirse los criterios de representación: si se tomaría por base única a la población, la extensión del territorio o las contribuciones directas. Finalmente, que la representación quedara como estaba, dejando a la comisión de constitución resolviera lo pertinente para las Cortes futuras.

Dijeron también que otorgar la igualdad para las presentes Cortes no era práctico ni conveniente. Lo primero, porque requería mucho tiempo enviar las convocatorias, celebrarse las elecciones locales y hacer, los diputados electos, el viaje a la isla de León; que para cuando éstos llegaran, posiblemente ya habrían sido cerradas las sesiones de las Extraordinarias. Lo segundo, porque si por casualidad lograban llegar antes, quizá esos diputados cuestionarían lo ya aprobado por las Cortes, generando así un problema de difícil y lenta resolución.

Apoyaban sus argumentos en el contenido de la real orden del 14 de febrero de 1810 expedida por el Consejo de Regencia. Documento que, como mencionamos ya, convocaba a ultramar a enviar sus representantes, y efectivamente indicaba que las Extraordina- rias solucionarían para las futuras Cortes lo que en éstas hubiera sido inconveniente. Finalmente, los señores Valiente y Amer dijeron en la sesión del 9 de enero de 1811, que la prioridad era la pacificación del territorio americano y no su representación. ${ }^{28}$

El problema real por el que se negaban a conceder la representación igualitaria para esas Cortes no sólo era, como lo expuso el diputado de Asturias, el señor Agustín de Argüelles, la superioridad numérica del continente americano. ${ }^{29}$ Había motivos más significativos.

Como ha demostrado Manuel Chust los peninsulares se oponían a otorgar la representación igualitaria porque la fórmula propuesta por los americanos conducía a una monarquía española federal. ${ }^{30}$ Admitir más representantes americanos era reforzar esa propuesta de nación que no coincidía con el proyecto de los liberales peninsulares.

Los americanos argumentaron que defendían la igualdad declarada desde los Reyes Católicos, confirmada por las Leyes de Indias y reconocida por la Regencia y por las Cortes en el decreto

${ }^{28}$ Sesiones de las Cortes de los días 25 de septiembre, 1, 2, 3 de octubre de $1810 ; 9,11,16$, $18,20,23,25,30$ de enero; $1,7,9,13$ de febrero, 31 de abril y 14 de septiembre de 1811 , entre otras, en Diario, 1811-1823, varios volúmenes.

29 Este señor dijo que el problema central era que "en aquel hemisferio nos hallamos con una población que excede a la de la madre patria y con la dificultad de clasificarla". Sesión de las Cortes del 9 de enero de 1811 en Diario, 1811 1823, vol. Il, p. 322 .

30 Chust, Cuestión, 1999, pp. 57 a 59; "Vía", 1995 , pp. 159 a 187. 
del 15 de octubre de 1810. Expusieron que por razones de necesidad, justicia y conveniencia y para frenar las guerras independentistas, debían las Cortes decretar la igualdad de representación para las que se estaban celebrando y no para las futuras, como querían los peninsulares. Dijeron que no era justo tomarlos como iguales para la recaudación de impuestos desde ahora y no para participar en las decisiones de gobierno.

El debate se complicó cuando los americanos comenzaron cuestionando la legitimidad de las Cortes que se estaban realizando. No es justo, decían, que América no esté igualmente representada. El diputado por Nueva España, José María Gutiérrez de Terán, dijo: "es menester, señor, obrar y no hablar". ${ }^{31}$ El diputado Francisco López Lisperguer, de Buenos Aires, puso el dedo en la llaga al declarar que:

desde luego sabemos que está enferma [la América] pero sabemos que es la que únicamente ha de sostener nuestra guerra, y que si la perdemos, ni tendremos soldados, ni dinero, ni cosa alguna. [América ve] que los españoles pelean no como en la guerra de Sucesión, cuando lo menos en que se pensó fue en constituir sus derechos, sino que pelean por cortar la cabeza del despotismo y a la arbitrariedad. ${ }^{32}$

El 1 de agosto de 1811 los diputados americanos, cansados de solicitar la igualdad mediante la representación

31 Sesión de las Cortes del 9 de enero de 1811 en Diario, 1811-1823, vol. II, p. 317.

32 lbid, p. 325. equitativa y no ser escuchados por los diputados peninsulares, elaboraron otra representación a las Cortes. ${ }^{33}$ Su principal demanda era, una vez más, la igualdad de representación. Añadían a su lista el establecimiento de juntas provinciales que, como las de la península, ejercieran el gobierno de sus propios distritos. Afirmaban que el deseo de independencia de América se debía a la opresión del mal gobierno ahora representado por las Cortes. Decían que no querían que una junta sólo los mandase, sino que fueran escuchadas sus peticiones en el mismo nivel de igualdad que las de los diputados peninsulares; "que un pueblo no domine a otro, o una parte de la soberanía a la otra parte, requiriéndose la concurrencia de todas para formar un gobierno que goce el lleno de la soberanía". ${ }^{34}$

Y no sólo eso. Cuestionaron la legitimidad de las Cortes al no permitir que los americanos tuvieran sus propias juntas y casi justificaron la insurgencia:

En resumen, el deseo de independencia no es general en América, sino que es de la menor parte de ella. Aun ésta no la desea perpetua, y la que desea no es de los europeos, ni de la península, ni de la nación, ni del rey, ni de la monarquía, sino únicamente del gobierno que ve como ilegítimo. Por tanto su revolución no es rebelión $[. .$.$] sino un concepto u opinión de que no$ les obliga a obedecer a este gobierno. ${ }^{35}$

33 Alamán, Historia, 1990, vol. III, p. 49.

34 Representación de la diputación americana a las Cortes de España, 1 de agosto de 1811 en Alamán, Historia, vol. III, p. 381.

35 lbid. 
Insistían en que la solución de las desavenencias radicaba en que las Cortes declararan para éstas y para siempre la igualdad de representación. No se tomó resolución alguna, porque a los pocos días la comisión de constitución presentó sus trabajos para su discusión y aprobación, los que incluían el tema de la representación. ${ }^{36}$

En este ambiente se expidió el decreto de abolición del paseo del real pendón. Las demandas de la representación, como vimos, nunca fueron satisfechas; en su lugar, para convencer a los americanos de que eran considerados parte integrante de la monarquía en la misma calidad de igualdad, las Cortes decretaron la abolición del paseo del pendón. Ésta había sido solicitada el 26 de octubre de 1811 por el diputado de Montevideo, el señor Rafael Zufriátegui. ${ }^{37}$

En la sesión del 5 de enero de 1812 se presentó el dictamen que la comisión ultramarina otorgó a dicha petición. La comisión expuso que su opinión era a favor de la abolición, pues aunque ésta era una costumbre antigua, aprobada por el soberano y mandada observar por las Leyes de Indias, no era coherente con la nueva calidad que las Cortes habían otorgado recientemente a los americanos,

36 Sesión de las Cortes del 14 septiembre de 1811 en Diario, 1811-1823, vol. vII, pp. 300 y ss.

37 Manuel Chust afirma que esta petición estaba bloqueada y que aprovechando las discusiones sobre la representación americana, el diputado por Tlaxcala, José Miguel Guridi y Alcocer, logró reintroducirla en las sesiones de las Cortes. Chust, Cuestión, 1999, p. 194. pues que les ha dicho V. M. [las Cortes] que ya no habrá colonias, sino provincias entre sí iguales, partes integrantes e indivisibles de un poderoso imperio: por lo que no alcanza la comisión cómo podrá sustentarse esta igualdad con semejantes prácticas coloniales. ${ }^{38}$

Sugería que era necesario abolir todos los ritos que constituyeran una remembranza de la condición de conquistados y colonizados. Esas prácticas festivas, decía el dictamen de la comisión, no sólo contradecían la igualdad decretada por las Cortes, también generaban en los americanos sentimientos de inferioridad:

porque cuando la nación colocó a las provincias españolas americanas al lado de las españolas europeas derogó implícitamente estos actos, que a pesar de ser hijos de la lealtad, se sostienen siempre sobre el concepto relativo de inferioridad, o distinción odiosa que ha suprimido la Constitución. 39

La comisión señaló el significado político que la abolición del paseo del pendón, símbolo del poder absolutista en América, tenía entonces. Contribuiría a convencer a los americanos de que la igualdad no era falsa:

es necesario destruir la funesta persuasión en que se hallan los malcontentos, de que la igualdad proclamada por el gobierno español no es más que una bri-

\footnotetext{
38 Sesión de las Cortes del 5 de enero de 1812 en Diario, 1811-1823, vol. Xi, p. 149.

39 Ibid.
} 
llante quimera, para sujetarlos mejor a la esclavitud con hechos y providencias generales, que recayendo sobre una costumbre universal los conduzca al desengaño. ${ }^{40}$

El dictamen de la comisión aprobado por los diputados a Cortes el 7 de enero de 1812 se sumó al discurso político que las Cortes habían seguido: poseer el apoyo económico de América y la unidad del imperio aparentando haber adoptado como principio fundamental el de la igualdad política en ambos hemisferios. El decreto intentaba avalar las declaraciones de igualdad emitidas anteriormente pero no concedidas en la práctica. Fue pensado en términos de las necesidades peninsulares, y por lo mismo sólo refleja los intereses de los liberales de aquel hemisferio.

\section{REFLEXIÓN FINAL}

Ninguna o muy poca relación tenían estas fiestas ordenadas por las Cortes Generales y Extraordinarias de Cádiz con Napoleón. Fueron, más bien, el símbolo del rompimiento con el absolutismo real, con el despotismo y el poder arbitrario. Fueron la expresión simbólica del principio fundador del nuevo orden sociopolítico: la soberanía nacional.

Con funciones similares a las que cumplían las ceremonias del absolutismo real, los regocijos del Estado liberal debían fomentar la adhesión de la sociedad al nuevo sistema. Fijar en la

40 Ibid., p. 150. conciencia de los ahora ciudadanos sus bondades: los derechos individuales, la igualdad ante la ley, el amor a la patria, las obligaciones que como ciudadano se tenían con ella y la esperanza de que en la nueva organización política se concentraba el futuro promisorio de la nación.

\section{ARCHIVOS}

AHDF Archivo Histórico del Distrito Federal.

\section{BIBLIOGRAFÍA}

-Alamán, Lucas, Historia de Méjico. Desde los primeros movimientos que prepararon su independencia en el año de 1808 basta la época presente, Jus, México, 1990, 5 vols.

- Anna, Timothy E., La caída del gobierno español en la ciudad de México, MCE, México, 1987.

—_. España y la independencia de América, FCE, México, 1983.

Artola, Miguel, "La monarquía parlamentaria" en Miguel Artola (coord.), Las Cortes de Cádiz, Marcial Pons, Madrid, 1991. Marcial Pons, Madrid, 1991.

-Chust Calero, Manuel, La cuestión nacional americana en las Cortes de Cadiz, (18101814), Fundación Instituto Historia Social/ IIH, Valencia, 1999.

-, "La vía autonomista novohispana. Una propuesta federal en las Cortes de Cádiz", Estudios de Historia Novobispana, vol. 15, 1995, pp. 159 a 187.

-Colección de los decretos y órdenes que ban expedido las Cortes Generales y Extraordinarias desde su instalación de 24 de septiembre de 1810 
basta 19 de febrero de 1823, Imprenta Nacional, Madrid, 1820-23, 10 vols.

-"Constitución Política de la Monarquía Española” en Juan E. Hernández y Dávalos, Colección de documentos para la bistoria de la guerra de independencia de México de 1808 a 1821, José María Sandoval, México, 18771882, vol. IV.

-Diario de las discusiones y actas de las Cortes, Imprenta Real, Cádiz, 1811-1823, 23 vols.

-Díaz-Pla, Fernando, Historia de España en sus documentos, Siglo XIX, Cátedra, Madrid, 1983.

-Flaquer Montegui, Rafael, "El ejecutivo en la revolución liberal" en Miguel Artola (coord.), Las Cortes de Cádiz, Marcial Pons, Madrid, 1991.

-Garrido Asperó, María José, "La fiesta de San Hipólito en la ciudad de México, 1808-1821", tesis de licenciatura, UNAM, México, 1996.

"Las fiestas cívicas en la ciudad de México: de las ceremonias del Estado absoluto a la conmemoración del Estado libe- ral, 1765-1823", tesis de maestría, UNAM, México, 2000.

-Guerra, François Xavier, Modernidad e independencias. Ensayo sobre las revoluciones bispánicas, Mapfre, Madrid, 1992 (Col. Relaciones entre España y América, 16).

-Hamnett, Brian, La política española en una época revolucionaria, 1790-1820, FCE, México, 1985.

-Marcuello Benedicto, Juan Ignacio, "Las Cortes Generales y Extraordinarias: organización y poderes para un gobierno de asamblea" en Miguel Artola (coord.), Las Cortes de Cádiz, Marcial Pons, Madrid, 1991.

-Morán Orti, Manuel, "La formación de las Cortes, 1808-1810" en Miguel Artola (coord.), Las Cortes de Cádiz, Marcial Pons, Madrid, 1991.

-Rodríguez O., Jaime E., La independencia de la América española, FCE/El Colegio de México, México, 1998 (Serie Ensayos).

-Suárez, Federico, Las Cortes de Cádiz, Rialp S. A., Madrid, 1982.

-Solís, Ramón, El Cádiz de las Cortes. La vida en la ciudad en los años de 1810 a 1813 , Instituto de Estudios Políticos, Madrid, 1958.

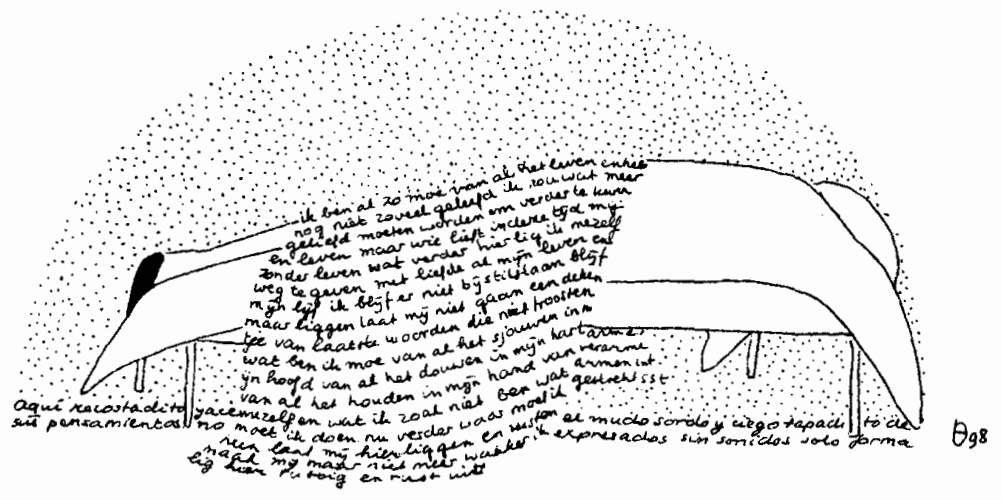

LOS REGOCIJOS DE UN ESTADO LIBERAL 